\title{
Finite element simulation and analysis of saw cutting
}

\author{
Dyi-Cheng Chen ", You-Hua Chen, Ci-Syong You, and Shin-Han Huang \\ Department of Industrial Education and Technology, National Changhua University of Education, \\ Changhua 500, Taiwan
}

\begin{abstract}
In this paper, Finite Element Analysis (FEA) used DEFORM ${ }^{\mathrm{TM}}$ 3D to construct 6061 aluminum sawing simulation. Before sawing, we pushed the speed and cutting speed under pressure as a sawing process parameters. Then there are three groups of combination conditions in the study. Analysis and discussion based on loading, effective stress, cutting temperature and blade wear. According to the impact parameters the structural design of the saw blade is improved by taking full account of the mutual influence of sawing parameters.
\end{abstract}

\section{Introduction}

In order to improve the processing efficiency and product surface quality, especially to meet the strict requirements of all types of parts, sawing is an important metal processing method. Finite Element Analysis (FEA) is an effective auxiliary design tool, which can represent the material properties of workpieces including the function of temperature, strain and strain rate. It fully considered the interaction between cutting parameters of sawing turning tools. According to the relationship between parameters improved the impact of structural design. Research on sawing machining includes: Toru et al. [1] heat-processes the cutting tool, transfers the heat from the heated cutting tool, and simulates the workpiece. Cutting experiments prove that the tool heating mode improves the machinability. Stepan et al. [2] verification is used to calculate the stability of fixed milling and to measure general numerical algorithms that are validated in the work environment. It is able to predict the stability conditions of the cylindrical milling cutter geometry during the milling process. Jaroslava and Zdenk [3] studied the tool life of cutting edge radii, which machining the steam turbine shell. Umbrello [4] used DEFORM ${ }^{\mathrm{TM}} 2 \mathrm{D}$ software to simulate the orthogonal cutting of titanium alloy, which changed the optimum cutting parameters of titanium alloy including the tool angle, temperature, velocity and feed rate. Diniz and Micaroni [5] compared the surface roughness with different feed rates, cutting speeds, dry cutting and cutting fluid analysis. Totis et al. [6] using a dynamic mathematical model through finite element analysis for cutting test to improved tool geometry optimization. The experimental results proved the excellent characteristics of the new device. Wang [7] compared with SCMT and CNMM positive angle turning tool for different feed rates, cutting depth during

Corresponding author:dcchen@cc.ncue.edu.tw 
the workpiece force analysis. CAKIR and ISIK [8] used finite elements to analyze the vibration frequency and the buckling strength during cutting. Mitrofanov et al. [9] used finite element analysis to analyse the temperature distribution of the tool and workpiece during orthogonal cutting. Ceretti et al. [10] used DEFORM ${ }^{\mathrm{TM}} 2 \mathrm{D}$ to simulate the effects of parameters on the turning process. Attanasioa et al. [11] used experimental and simulation results showing a positive correlation between wear and cutting speed or feed rate.

\section{Related theories}

\subsection{Finite element simulation analysis}

DEFORM $^{\mathrm{TM}} 3 \mathrm{D}$ software is based on the design system and machining process, through the two-dimensional or three-dimensional flow deformation of the analytical model to simulate the metal material on the mold forming, ductile damage values, deformation temperature, plastic flow velocity, stress and strain distribution situation. This software can greatly save the time and money of mold-testing. And it can provide important information, such as the impact of different materials and heat conduction on the finished product.

During the forming process, due to the impact of plastic deformation, the processing of defects are mostly caused by ductile material damage. The brittle fracture of metal material is based on the microscopic phenomenon that the crystal cracks and the atoms are mutually combined and destroyed that is the "Cleavage fracture". The amount of strain generated prior to material failure is minimal or no plastic deformation and no early warning of damage. Chen et al. [12] revised the "Cockcroft \& Latham" guidelines to formulate a nondimensional decision rule called "Normalized C \& L criterion" :

$$
\int_{0}^{\bar{\varepsilon}_{f}} \frac{\sigma_{\max }}{\bar{\sigma}} d \bar{\varepsilon}=C
$$

where $\sigma_{\max }$ is the maximum tensile stress, $\bar{\varepsilon}$ is the effective strain, $\bar{\sigma}$ is the effective stress, $\bar{\varepsilon}_{f}$ is the effective strain at failure, and $\mathrm{C}$ is the damage value.

Mold wear calculation model: To analyze the mold wear which selected the wear calculation model, DEFORM analysis software gives two calculation models. Here choose Archard wear mode, the formula as follows:

$$
Z_{A B}=\int K \frac{p^{a} v^{b}}{H^{c}} d t
$$

In the formula, $Z_{A B}$ is worn, $p$ is the contact pressure, $v$ is the relative velocity, $H$ is the hardness of the mold, $d t$ is the increment time, $a$ and $b$ are experimentally coefficients; $a=1$, $b=1, c=2$ and $K=0.000002$.

\subsection{Saw blade cutting}

Figure 1 shows sawing schematic diagram of 6061 aluminum alloy using finite element analysis. It is interface shear friction as 0.12 and interface heat transfer coefficient as 0.004 . The hardness of 6061 aluminum is 54 and initial temperature as $68^{\circ} \mathrm{F}$.It can be seen that the Fig.1 (a) is before processing, Fig.1(b) is during processing, Fig.1(c) is after processing. The tool material is a rigid material and the displacement in the $\mathrm{x}, \mathrm{y}$, and $\mathrm{z}$ directions of the workpiece boundary condition is completely fixed. It can be seen in Figure 2-Figure 4. 


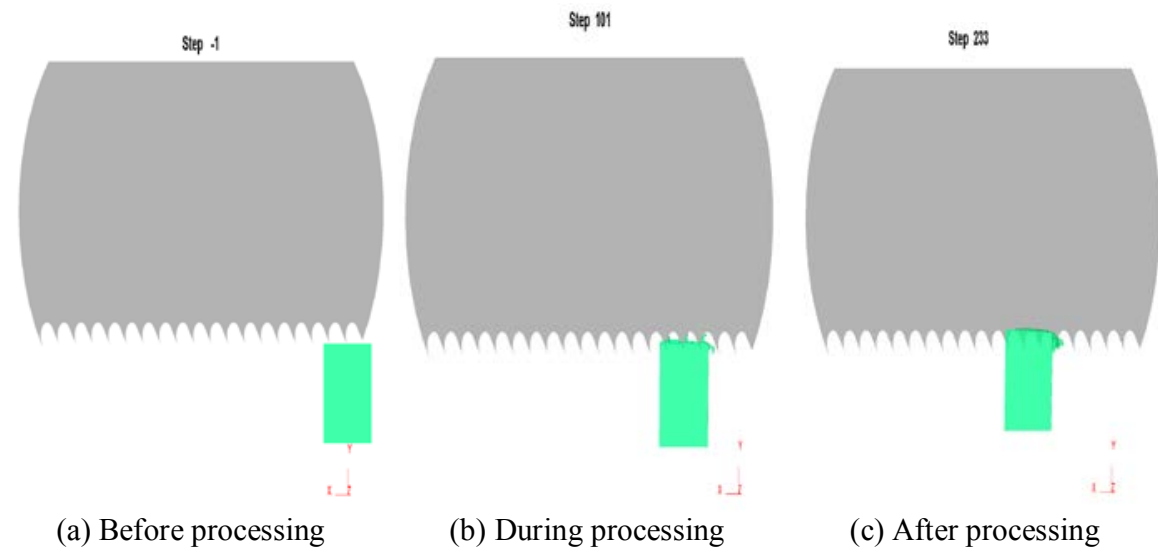

Fig. 1. 6061 aluminum alloy sawing schematic diagram.

The workpiece material selects 6061 aluminum alloy (6061), and the tool material uses high speed steel. The displacement of the workpiece in the $\mathrm{x}, \mathrm{y}$ and $\mathrm{z}$ directions are completely fixed. Figure 2 is the half-section of before sawing. Figure 3 shows the halfsection of during sawing. Figure 4 shows the half-section of after sawing.

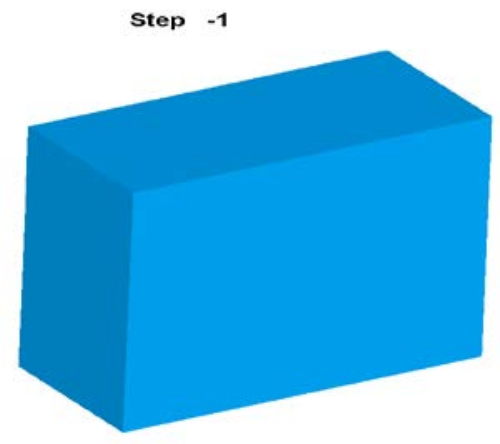

Fig. 2. Before sawing for 6061 aluminum alloy.

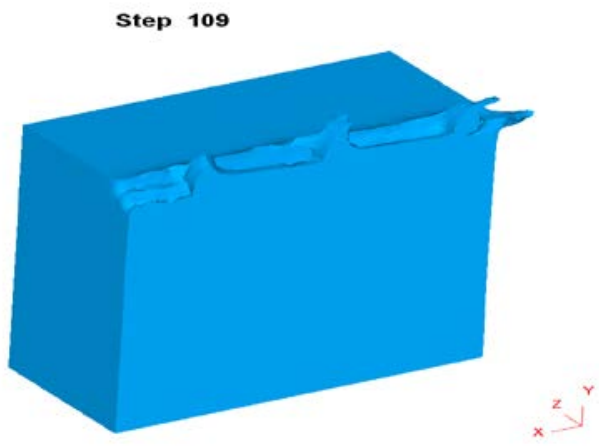

Fig. 3. During sawing for 6061 aluminum alloy. 


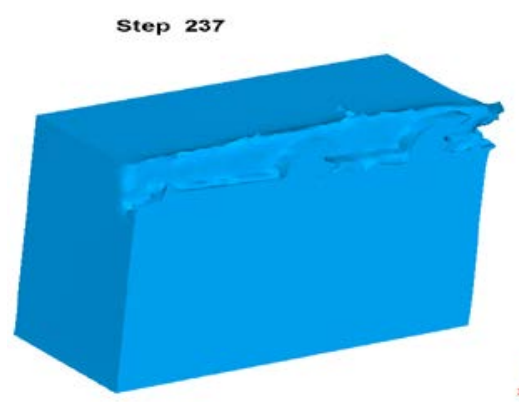

Fig. 4. After sawing for 6061 aluminum alloy.

\section{Results and discussions}

Table 1 presents a simulation parameter table for the sawing speed difference, which setting the simulation analysis of the change parameter, forward speed of $2,4,6 \mathrm{~mm} / \mathrm{sec}$, and the pressing speed of $0.2,0.4,0.6 \mathrm{~mm} / \mathrm{sec}$.

Table 1. Simulation parameters table.

\begin{tabular}{|c|c|c|}
\hline Numbering & $\begin{array}{c}\text { X-axis forward speed } \\
(\mathrm{mm} / \mathrm{sec})\end{array}$ & $\begin{array}{c}\text { Y-axis downward pressure speed } \\
(\mathrm{mm} / \mathrm{sec})\end{array}$ \\
\hline 1 & 2 & 0.2 \\
\hline 2 & 4 & 0.4 \\
\hline 3 & 6 & 0.6 \\
\hline
\end{tabular}

Figure 5 shows no. 1 saw blade of the X Load (N) analysis. It can be seen that the load increases with the increasing time, which indicates that the bigger thrust can saw the material. Figure 6 presents no. 1 saw blade of the Y Load $(\mathrm{N})$ analysis. It can be seen that the load increases with the increasing time. It indicated that the using greater downward pressure to saw the material. Figure 7 presents no. 1 saw blade of the Z Load (N) analysis. It shows the maximum load of $20.8 \mathrm{~N}$, and large difference between $\mathrm{X}$ load and $\mathrm{Y}$ load. The line shape produced up and down shock. It can be seen that the sawing Z-axis has no effect. Figure 8 compared with $\mathrm{X}$ Load $(\mathrm{N})$ between no. 1, no. 2 and no. 3 at the same sawing depth that the each number's load is about $200 \mathrm{~N}$. It indicates there is no significant relationship between the sawing speed and X load.

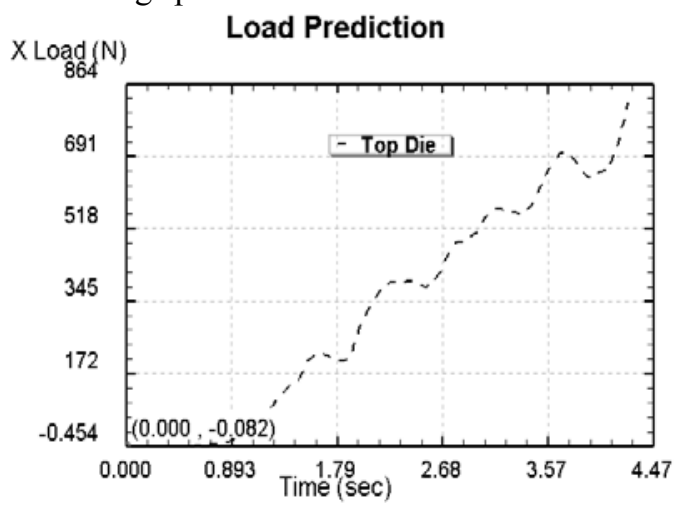

Fig. 5. X Load (N) analysis for No. 1 saw blade. 


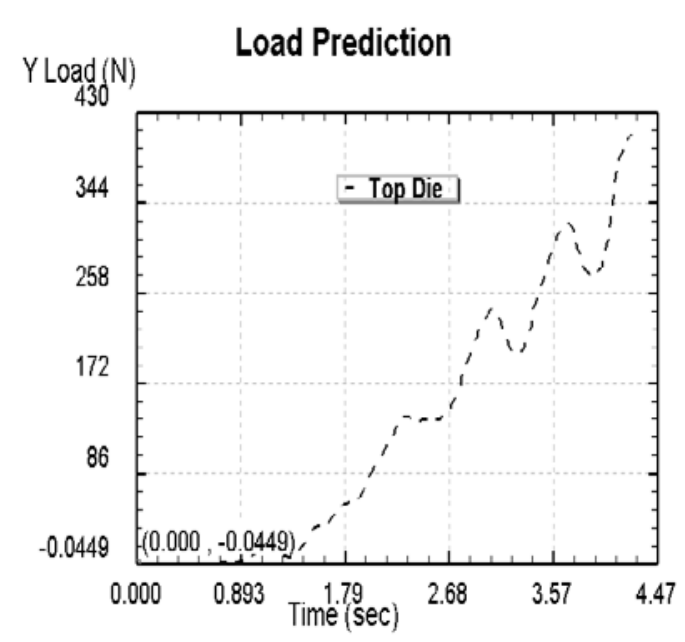

Fig. 6. Y Load (N) load analysis for No. 1 saw blade.

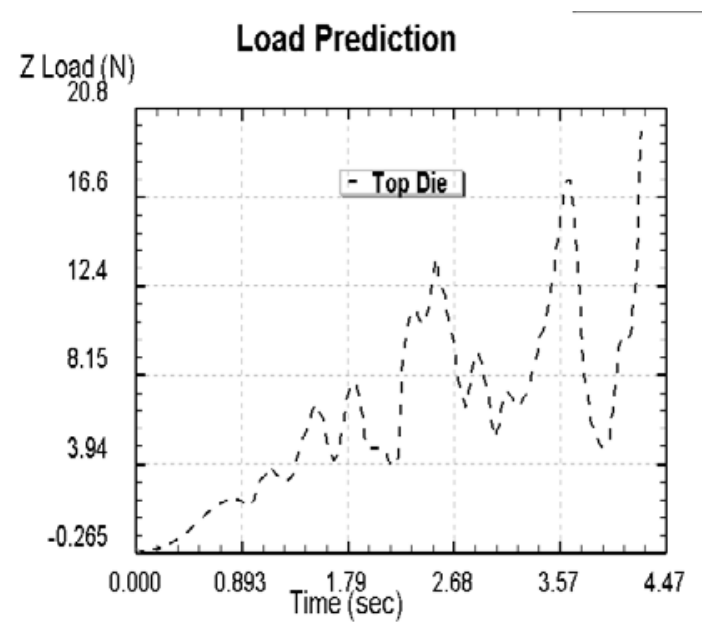

Fig. 7. Z Load (N) load analysis for No. 1 saw.

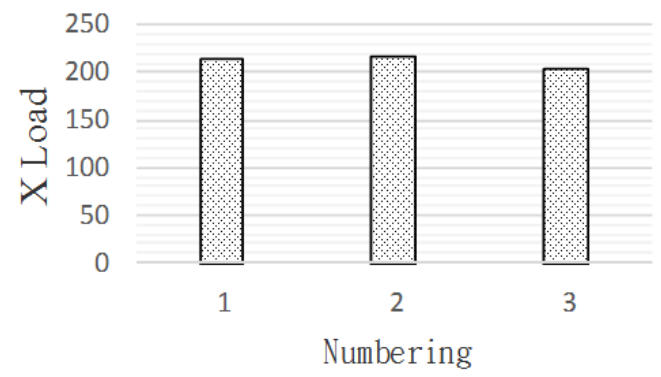

Fig. 8. Comparison chart on X load (N).

Figure 9 compares the temperatures with each number of saw blades. It can be seen that the higher sawing speed causing the lower temperature, but less significant. Figure 10 shows the temperature analysis of aluminum alloy, when the sawing time increases, the material temperature is increased. Figure 11 shows the temperature simulation of 6061 
aluminum alloy. It can be seen that the temperature is evenly distributed in the upper half of the sawing material.

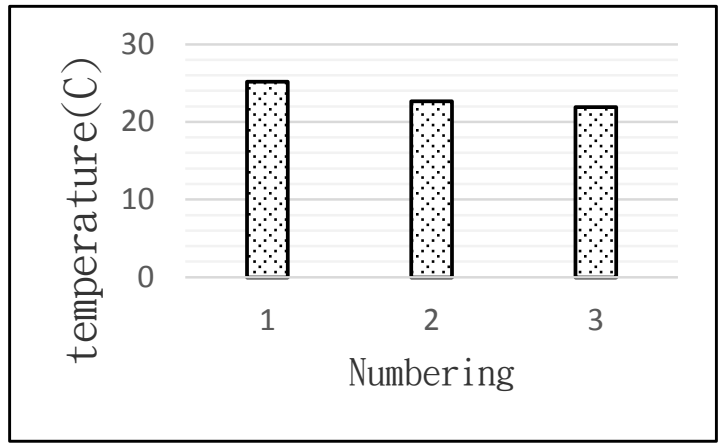

Fig. 9. Comparison chart of saw blade temperature for each number.

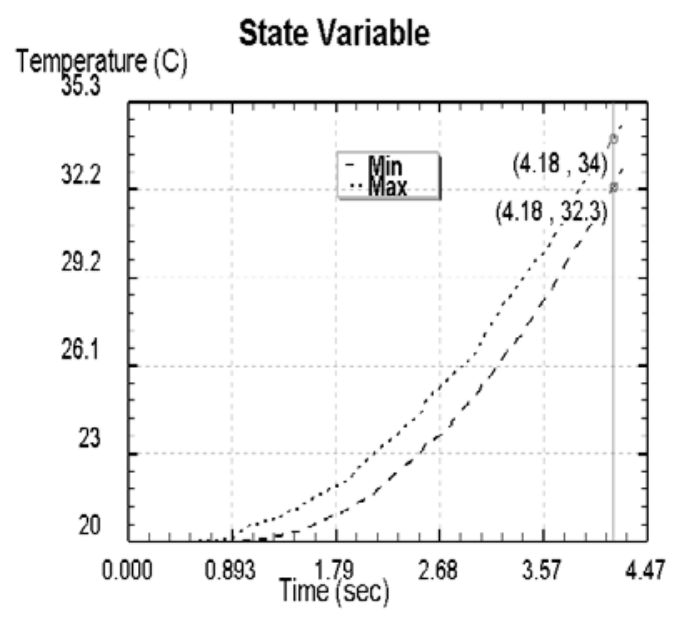

Fig. 10. Temperature analysis of 6061 aluminum alloy.

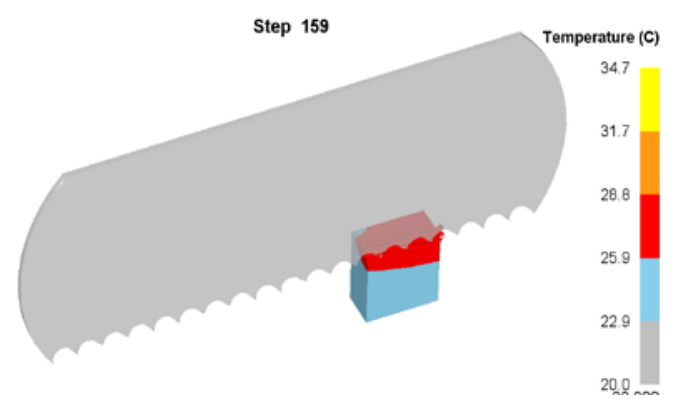

Fig. 11. Temperature simulation of 6061 aluminum alloy.

Figure 12 shows the comparison of effective stress for 6061 aluminum alloy. It can be seen that sawing speed and effective stress no significant relationship. Figure 13 shows the effective stress simulation for parameter no. 1. The maximum of effective stress concentrates on the contact area between the serration tip and the workpiece. The contact between saw teeth and chip produces stress to cause bending. Figure 14 shows the effective stress analysis. The effective stress shows stable trend after 1 second. Figure 15 simulation the wear of saw blade. The rightmost saw tooth wear is minimum and the leftmost relative 
maximum wear, because the rightmost teeth contact material less time, and the left tooth contact material longer time. The largest wear part of saw tooth is occurred on the saw tooth tip.

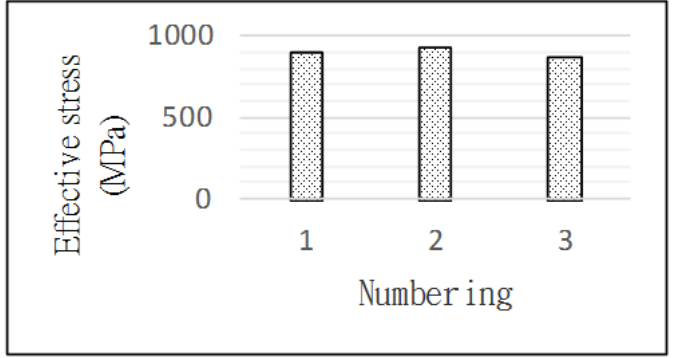

Fig. 12. Effective stress comparison chart of 6061 aluminum alloy.

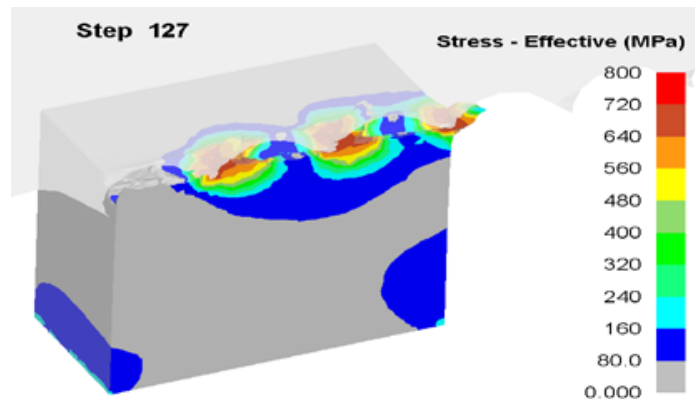

Fig. 13. Effective stress simulation of 6061 aluminum alloy.

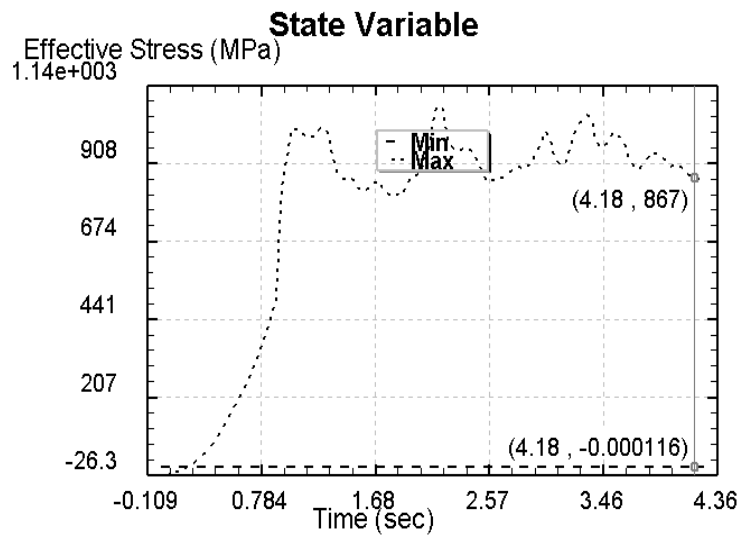

Fig. 14. Effective stress analysis for No.1 aluminum alloy.

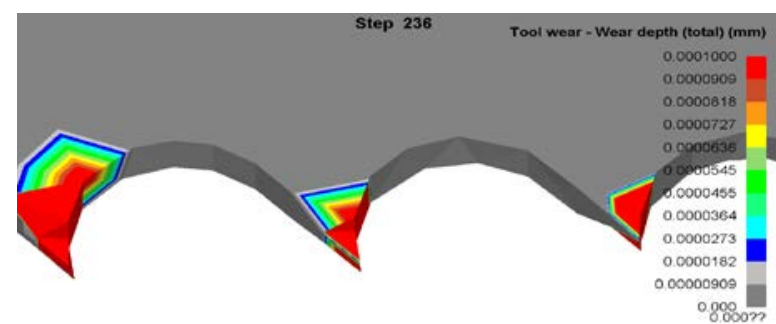

Fig. 15. Saw blade wear simulation. 


\section{Conclusions}

In this paper, Finite Element Analysis (FEA) used DEFORM ${ }^{\mathrm{TM}} 3 \mathrm{D}$ to construct 6061 aluminum sawing simulation. The results simulated are as follows:

There is no guide angle to allow the cutting edge to smoothly cut in when the first tooth cuts into the material. It cause the aluminum alloy produced a greater stress. A stable cutting process is occurred after the second tooth entered. The maximum stress from cutting is occurred the site where the point and the tip touches. Effective strain increases with an increase of blade feed, and the effective strain is distributed higher at the end of the cutting process. Chip is accumulated in the end and has a greater effective strain. Initial contact to the material produces an instantaneous high temperature. The temperature increases with an increase of cutting edge feed, and the highest chip temperature has just formed. The largest part of the wear is the sharp edge of the tool, and the maximum depth of simulated wear is $0.0001 \mathrm{~mm}$.

\section{References}

1. K. Toru, H. Kanako and M. Mamoru, CIRP Annals - Manufacturing Technology, 36, 105-108 (2014)

2. G. Stepan, J. Munoa, T. Insperger and M. Surico, CIRP Annals - Manufacturing Technology, 63, 385-388 (2014)

3. F. Jaroslava and J. Zdenk., Procedia Engineering, 69, 565-573 (2014)

4. Umbrello, Journal of Materials Pressing Technology, 196, 79-87 (2008)

5. A.E. Diniz and R. Micaroni, International Journal of Machine Tools \& Manufacture, 42, 899-904 (2002)

6. G. Totis, O. Adams, M. Sortino, D. Veselovac and F. Klocke, Measurement, 49, 164$181(2014)$

7. J. Wang, Journal of Materials Processing Technology, 97,114-119 (2000)

8. M. Cemal CAKIR and Y. ISIK, Materials and Design, 26, 105-112 (2005)

9. A.V. Mitrofanov, V.I. Babitsky and V. V. Silberschmidt, Journal of Materials Processing Technology, 153-154, 233-239 (2004)

10. E. Ceretti, C. Lazzaroni, L. Menegardo, T. Altan, Journal of Materials Processing Technology, 98, 99-103 (2000)

11. A. Attanasio, E. Ceretti, A. Fiorentino, C. Cappellini, C. Giardini. Wear, 269, 344$350(2010)$

12. C.C. Chen, S.I. Oh and S. Kobayashi, Ductile Fracture in Axisymmetric Extrusion and Drawing, J Eng. Ind., 101-102, 36 (1979) 